\title{
Mobile Advertising Optimization Strategy Based on SICAS Model in China
}

\author{
Liu Jingyan ${ }^{1} \&$ Huang Liwen ${ }^{2}$ \\ ${ }^{1}$ International Business School, Jinan University, Zhuhai, China \\ 2 Management School, Jinan University, Guangzhou, China \\ Correspondence: Liu Jingyan, International Business School, Jinan University, Zhuhai, China. E-mail: \\ 45106503@qq.com
}

Received: August 20, 2018

doi:10.5539/ijbm.v13n11p169
Online Published: October 12, 2018

URL: https://doi.org/10.5539/ijbm.v13n11p169

\begin{abstract}
Mobile Internet changes consumer behavior, which also changes marketing. Mobile advertising is an important part of mobile marketing. This paper aims to describes consumer behavior in the mobile internet and provides guidance for mobile advertising. This paper applies inductive and deductive method to analyze mobile advertising's role in the consumption process based on SICAS model, and then put forward the optimization strategy. Mobile advertising starts with acquiring consumers for products and services, obtains consumer demand through online senses; and realizes interactive connection with consumers to provide the valuable solutions; recommends the brands to meet consumer demands and form the flow from online to offline; feedback online through social sharing after using mobile payment to complete the transaction, to form a complete closed-loop mobile business. Mobile advertising can be be optimized in advertising delivery, advertising content and advertising communication. The precise delivery is achieved through tagged consumer and programmatic purchase. Content advertising, as the core of mobile advertising, is influenced by location, creative experience and scene. Native advertising that content is advertising provides good consumer experience. Cross-screen communication and social communication increases the communication performance of mobile advertising. This paper contributes to the understanding and improvement of mobile advertising, and its findings provide the new thinking perspective for mobile advertising.
\end{abstract}

Keywords: SICAS, mobile marketing, mobile advertising

\section{Introduction}

The development of mobile Internet has brought about changes in consumer behavior. The consumer scenes open up online and offline from the traditional PC Internet to mobile Internet. A variety of rich content experience and consumption upgrades happen to consumers, and marketing methods have changed under the mobile Internet environment. Mobile Internet is influencing the traditional forms of advertising communication, constantly challenging the cost-effectiveness of traditional advertising, and increasing the demand for advertising content and advertising expression forms. With the continuous penetration of mobile media, mobile advertising has become the new normal for brand marketing. The mobile-side information dissemination is characterized by specificity, accuracy and interactivity. Compared with the full delivery of traditional advertising, mobile advertising can achieve precise delivery, convenient and timely, free from geographical restrictions and show better marketing performance and greater commercial value. This paper analyzes the consumer behavior and consumption path in the mobile internet, applies SICAS model for the mobile advertising, and puts forward the advertising optimization strategy to provide reference for the mobile advertising.

\section{Literature Review}

The transformation of consumer behavior has led to the changes of marketing methods. In the aspect of consumer behavior model, it has undergone three stages: AIDMA, AISAS and SICAS. AIDMA model under the traditional marketing corresponds to Mass Media and Mass Market's broadcast marketing and describes the consumer shopping decision process in the traditional marketing environment. AIDMA believes that consumers experience five stages from the contact with information to the final purchase: Attention, Interest, Desire, Memory, and Action. AIDMA promotes the entire marketing process through traditional advertising marketing 
methods, and realizes the wide communication of information.

In the age of PC Internet, the guiding effect of AIDMA model has been continuously weakened. Japan Dentsu Group (2005) proposed AISAS model: Attention, Interest, Search, Action, and Share, which emphasizes that consumers independently search for information and share experience after completing purchase behavior. Consumers search Internet for the interesting product information, decide whether to purchase, and actively share their shopping experience to more consumers. AISAS model corresponds to consumers actively searching for information and actively responding to shopping results, but consumers are still passively accepting advertisement information. The Internet provides consumers with the convenience of information search during the consumption process. It is still a one-way marketing communication process, focusing on obtaining consumer attention more than consumers sharing.

In the age of mobile Internet, consumer behaviors and marketing methods are more open and complex, changing the entire consumption process from a one-way communication to a two-way interactive sense connection. DCCI (Data Center of CHINA INTERNET) (2011) proposed SICAS model to deconstruct the multi-point two-way consumer behavior and provided guidance for marketing decisions. SICAS model includes five stages: Sense between the brands and consumer, Interest \& Interactive, Connect \& Communication, Action and Share. SICAS model corresponds to changes in consumer behaviors and consumption patterns in the consumption process, and analyzes the links among consumer information contacts, consumer behaviors, consumption paths and the communication between consumers, consumers and the brands from a variety of perspectives of media, channels, and scenes. During the entire consumer process, consumers take the initiative in information attention. Consumers gradually change from passive one-way receiving information to actively acquiring, collecting and sharing information, actively involved in the creating, sharing and disseminating information. SICAS model demonstrates "relationship matching-interest coupling-experience sharing" marketing focusing on consumers rather than products. In such a communication environment, advertisers sense and respond to consumers demand in real-time, establish multidimensional interactions between advertising and services, relying on reliable and convenient entrances for consumption and actively undertaking the dissemination of advertisements.

SICAS model constructs the theoretical model to understand consumer behavior in the digital age, and has been continuously verified in digital marketing activities in China. Many researcher apply SICAS model for social networks communication and social marketing (Li, 2013; Jiang \& Yang, 2013; Yang, 2011; Zhang \& Liu, 2014; Zhang \& Bi, 2016; Zhang, 2013; Yan, Hu, Xu, \& Liu, 2017), and the dissemination and development of online advertising (Ren \& Zhao, 2012; Wang, 2013), but there are still few research applications for mobile advertising.

\section{Mobile Advertising Analysis Based on SICAS Model}

Consumer behavior patterns have changed in the age of mobile Internet. Mobile advertising starts with acquiring consumers for products and services, obtains consumer demand through online senses; and realizes interactive connection with consumers to provide the valuable solutions; recommends the brands to meet consumer demands and form the flow from online to offline; feedback online through social sharing after using mobile payment to complete the transaction, to form a complete closed-loop mobile business.

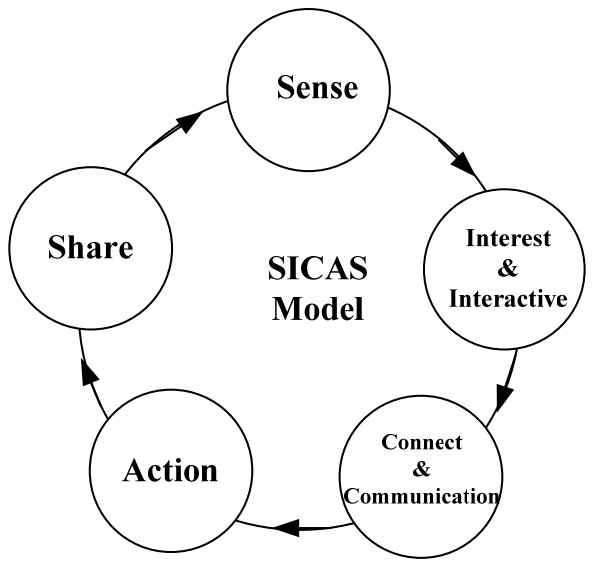

Figure 1. SICAS model 


\subsection{Sense}

Establishing sense networks between the brands and consumers is the foundation of mobile marketing. Social media and LBS (location-based services) can all be used to establish an interactive sense network. For the brands, the real-time sense of the entire network can fully sense consumers and be sensed by consumers, timely sense consumer needs and experience reviews, understand the consumption value orientation, discover and predict consumer trends, and realize dynamic response and effective contact, which is sensed by consumers in the most appropriate way. For consumers, they can choose the brands they are interested in anywhere and anytime. Click, push, subscription, follow, share, automatic matching and location services are implemented to achieve effective sense.

\subsection{Interest \& Interactive}

The effective interaction on the sense network enables consumers to resonate with consumers based on interest coupling, and expresses their preferences through the topics, popularity and follow. Interaction lies not only in the effective sense, but also in the way of interaction, the topic content and the interrelationship. Consumers express their attitudes on social platforms, then word of mouth effect is generated, understood, followed, and responded to consumers interests and needs through the social network, by which consumers are interested in mobile advertising content and interaction.

\subsection{Connect \& Communication}

Brands and consumers should connect and interact with each other in varying degrees. Different advertising systems and content service are integrated based on advertisement, content, and relationship networks. Combining mobile Internet and PC internet, accurate brand information is delivered to the target consumers through cross-screen marketing to observe consumer behavior from the consumer's point of view and establish an adequate communication and interaction mechanism to deepen familiarity of the brands.

\subsection{Action}

Consumer purchasing behavior not only occurs in the e-commerce platform, mobile app and social network may become the origin of the purchasing. Mobile advertising is a medium for increasing brand exposure and stimulating consumption while mobile payment and LBS are indispensable to realize sales conversion. Mobile applications, mobile e-commerce, and mobile payment can be integrated to increase promotions and discounts for mobile consumer. At this stage, mobile applications will pay attention to the connection rate with the e-commerce platform and the conversion of e-commerce data.

\subsection{Share}

Consumers often use social platforms to express their personalities and attitudes. Experience sharing is automatically distributed and dynamically aggregated on social networks, more complex than word-of-mouth marketing. Consumer experience sharing is becoming the source of consumption rather than the end of the consumer process to a large extent. Social relationships among consumers have become the key of enterprise marketing. Consumers express their feelings for products or services on social platforms, share experience with each other, and influence relevant consumers in the social network. The capability of discovering key information in experience sharing is essential to satisfy consumer needs and improve consumer productivity.

\section{Optimization Strategies for Mobile Advertising}

Mobile consumer behaviors are more private and more fragmented. Consumer usage time and diversification of mobile media has promoted the development of mobile advertising. Websites, social platforms and advertisers can make full use of the characteristics of mobile devices to interact with advertising content, to achieve precise delivery based on big data involved consumer attributes, geographic location and other indicators, and to improve the efficiency of mobile advertising. In order to match the characteristics of mobile consumers and explore the value of mobile advertising, mobile advertising strategies can be optimized in advertising delivery, content, and communication channels.

\subsection{Optimization of Advertising Delivery}

To achieve precision marketing in big data environment, the advertising delivery needs the change from the media-orientation to the crowd-orientation. The previous media-oriented delivery was relatively simple, focused on the network flow, concerning the match of media content and network flow, so it was extensive and inaccurate. The crowd-orientation delivery precisely matches and targets the consumer through in-depth analysis of multidimensional data such as online behavior, offline location and consumer attributes, so as to optimize the delivery through tagged consumer and programmatic purchases. 


\subsubsection{Tagged Consumer}

To tag consumers is the first step of achieving precise delivery. The specific content of the tagged consumer includes: mobile demographic attributes and consumer acceptance variables. Demographic attributes include age, gender, educational background and geographic location, as well as common time and location and mobile access methods. The mobile consumer acceptance variables influence consumers' usage of mobile advertising, such as entertainment sharing, information search, life status, and emotional level. Through the basic consumer tag refinement combined with online behavior and offline location, the target consumer characteristics can be determined. The consumers are tagged by using big data to crawl every consumer's Internet access path and analyze mobile consumers profile: male or female, how old, marriage or not, permanent city, career, the income, the habit of surfing the Internet, mobile device preferences, time period for using mobile devices, content preference and so on. Consumer interest and behavior preference are described to achieve precision marketing based on the personalized demand of consumers.

\subsubsection{Programmatic Purchase}

After tagging consumer, the target consumers of brand are segmented. According to mobile usage habits of target customers and recent search keywords, potential preferences brands and products are automatically pushed to consumers. The precise delivery of mobile advertising relies on emerging programmatic purchasing methods, by which the content of advertisements is intelligently delivered to the platforms and media strategies are continuously adjusted through real-time data feedback.

Programmatic purchase is suitable for the fragmented mobile advertising. Through automatic matching of supply and demand, labor and business costs are saved, and behavior tracking and intelligent dynamic allocation to cross-screen consumers are achieved. Programmatic purchases can be made on DSP (Demand Side Platform), Ad Exchange (advertising trading platform) by the way of RTB (Real Time Bidding) mode or NON-RTB (NON Real Time Bidding) mode. With the development of programmatic purchases, the current non-public auction methods such as PMP (Private Market Place) and PDB (Programmatic Direct Buy) are more popular. PDB can ensure the visibility of advertisements and brand safety, and is more in line with brand advertisers.

\subsection{Optimization of Advertising Content}

Content marketing has gradually become the mainstream of advertising. The effectiveness of mobile marketing depends not only on the media exposure of advertising, but also the communication experience. Advertising content is essential to influence consumer experience. Content advertising, which is the core of mobile advertising, transforms advertising marketing information into the content that consumers want. Advertising content focuses on media resources and big events, and is deeply embedded into product and service. Stream advertising and creative advertising are integrated to achieve strong content relevance. Native advertising provides valuable and meaningful content tailored to the consumer to satisfy the need of their lifestyles, to present brand information, and to appeal emotions and form consumer resonance.

\subsubsection{Influencing Factors of Advertising Content}

Advertising content not only requires the ad platforms to be highly integrated and provide creative advertising, but also has a high degree of relevance to the promoted consumer. Relying on big data analysis of the consumer segment, consumer characteristics are performed data mining and analysis to get personalized consumers profile, which helps the brands target consumers, precisely match marketing content, and make the content of the native advertising more targeted.

\section{1) Location}

Location service advertising is the most popular form of mobile advertising, with less than $10 \%$ of consumers taking a negative attitude toward it. In the content of location advertising, consumers are more willing to accept shopping, catering, entertainment and travel advertising. Location service is one of the indicators that reflect the behavior patterns of consumers. Based on consumer characteristics and brand preferences, the location of consumers can be a powerful tool that describes the urgency of consumer demand. Consumer demand is highly correlated with the scenes which may easily affect short-term temporary consumption. By digging into the consumer's motivation and consumer's location, it is possible to combine effective consumer behavior and geographic location for effective marketing and to implement content-based, action-friendly personalized mobile advertising campaign.

\section{2) Creative Experience}

The creative execution of mobile advertising needs location, time, weather, or other elements to provide 
consumers with meaningful and relevant experience, so as to attract consumers and influence their consumption behavior. Product service performance and advertising creativity are integrated through in-depth analysis of the local target consumer behavioral characteristics and consumption paths, to provide a variety of advertising forms focusing on ad copy, relevance, preferential information and visual and sound effects, and to create the content that cause consumer emotional resonance and goodwill.

\section{3) Scene}

The boundary between the online and offline scenes has become increasingly blurred, and both show a convergence trend. Scene marketing starts from offline, connects online scenes, and then acts on offline scenes to achieve closed-loop scene marketing. At present, most of mobile scenes focus on catering, shopping, leisure, travel and family scenes. In the mobile scenes, the scenes of clicking ads mostly happen in shopping, chatting with friends, reading news, watching videos, searching information and social networks. Different advertising information and call for action are considered according to the consumption stage and location of the consumer to construct demand scenes and push advertising content that can reinforce the brands and provide useful information.

\subsubsection{Native Advertising}

In mobile advertising, native advertising that content is advertising, providing the better consumer experience with the broader applications and stronger interaction, is valued by mobile platforms and advertisers. Native advertising is not just a sudden presentation of the consumer attention, but the depth content implantation. It fully meets consumer demand, makes consumers willing to participate and share. It is not a simple one-way "end-of-service" advertising, but a consumer-centric interactive sharing and new consumer experience.

With the support of the personalized recommendation engines and information flow, consumer profile is more accurate and clear, so that native ads are able to perform better and attract consumers to contact more advertising content by continuous supplement of new information. Traditional advertising is focused on the USP ((Unique Selling Proposition) of brand reputation, emphasizing the comprehensive advantages of the brands with the same or similar content. Mobile advertising focuses on UBP (Unique Buying Proposition) of consumer experience, emphasizing the long-term win-win relationship between the brands and the consumer in which advertising is content and then content provides experience. It realizes the emotion in the scenes and set up consumer-participating marketing to achieve the brands differentiated competitive advantage with precise delivery.

\subsection{Optimization of Advertising Communication}

\subsubsection{Cross-screen Communication of Advertising}

Single-screen mobile or online marketing can no longer satisfy advertisers' demand of contacting and impacting on the consumer in multiple scenes. Cross-screen communication has two-way complementary advantages, and consumers may use multiple screens for content consumption at the same time. It is also possible to transfer between multiple screens in consumer behaviors. The combination of large screen and small screen is a kind of integration of resources in all media sources. The same advertisement can be effectively complemented by communicating on multiple platforms. More consumers touch points make it easier for the brand values deeply rooted into the mind of the consumer. The data from the cross-screen feedback can provide more comprehensive insight into content consumers to improve content and technology.

Cross-screen identification technology is not yet mature at present. Cross-screen programmatic purchasing is mainly supported by the DSP intelligent dynamic allocation of cross-screen advertising budget to help advertisers in precision advertising delivery. According to marketing scenes of different screens and integrated cross-screen data, appropriate advertisement ideas can be delivered to different consumers so that the right consumer can see the right advertisements at the right time on the right screen. Cross-screen delivery of "PC + mobile + DSP " will be an important growth point for the subsequent advertising.

\subsubsection{Social Communication of Advertising}

When consumers fully participate in advertising, their roles change from the receiver to the experiencer and the information distributor, which make the effectiveness of advertising multiplied under the conversion of social attributes. The strong social attributes of mobile Internet will increase the stickiness of social platforms. The results of social advertising have been greatly enhanced by the form of native stream advertisements based on social networks. Social interaction sharing increases the ads click rate and achieves the brands exposure through viral communication. Advertising has more commercial value in the social platforms such as WeChat, Weibo, Toutiao and other online communities in China. At the same time, as a distribution center for opinions and 
suggestions, social platforms can effectively analyze the effectiveness of advertising, form interactive feedback with consumers, and make reasonable adjustments for the advertising effect.

The social communication of mobile advertising can be optimized in the following three ways. The first way focuses on the topic effect, which makes some interesting topics continuity, and then promotes them through websites, Weibo, Wechat, Toutiao, online community and other social platforms to continuously interact with consumers and enable consumers to actively accept brand information. For example, Starbucks opens \#My Starbucks Idea\# page on its website and social platforms to encourage consumers to customize products according to their preferences and vote on others' proposals. Starbucks will put the highest-valued into mass production and sales. The activity got a lot of feedback and forwarding from consumers in the short term. The second way focuses on the entertainment effects of UGC (User-Generated Content) and PGC Professional-Generated Content). UGC and PGC content is very suitable for viral marketing on social media. For example, the ice bucket challenge was generated and swept the world in the form of short video via social media. The third way focuses on opinion leaders, Internet celebrities and talents in the community, makes use of the fan effect in the target consumers to make consumer keep a deep memory and favorable impression on the brands.

\section{Conclusion}

Online advertising focuses on network flow, obtains consumer attention through the entry-level products and is aimed at obtaining profits through the flow performance. Mobile advertising focuses on content, acquires consumers with the ultimate products and services, and provides better consumer experience through the integration of resources. Based on SICAS model, we can deeply understand the changes in consumer behaviors, and then optimize the mobile advertising strategy to meet the demand of consumers for precise delivery, integrate advertising content into social life and achieve better advertising performance.

\section{Acknowledgments}

The paper is supported by the Science and Technology Planning Project of Guangdong Province, China (Project No. 2014A070703024).

\section{References}

Ali Research. (2014). SICAS: user behavior change and commercial mobile conversion. Retrieved November 2nd 2014 from http://www.aliresearch.com/blog/article/detail/id/19799.html

DCCI Data Center of China Internet. (2011). Bluebook of Chinese social marketing. Retrieved from hrrp://www.dcci.com.cn.

Huang L. J., \& Xia X. M. (2015). A Literature review of mobile marketing. Foreign economics \& management, 37(10), 58-68. https://doi.org/10.16538/j.cnki.fem.2015.10.005

Iresearch. (2014). China mobile program purchasing industry report. Retrieved August 18, 2014 fromhttp://www.iresearch.com.cn/report/2243.html

IResearch. (2016). China Internet Advertising User Behavior report (Brief). Retrieved March 31, 2016 from $\mathrm{http}: / / \mathrm{www}$. iresearch.com.cn/report/2564.html

Li, L. (2013). Research on the marketing communication model of library service based on SICAS. Library, (6), 10-13.

Jiang, J., \& Yang, Z. Y. (2013). Transformation Model from Attention and Intention to Sales on Experience Economic. BCGIN '13 Proceedings of the 2013 International Conference on Business Computing and Global Informatization,473-476

Mo, M. F., \& Zhang, Y. W. (2014). Cross-screen Portfolio Strategy for enterprise Marketing. Enterprise Management, (2), 117-119

Ren, T. H., \& Zhao, J. (2012). Research on network advertising communication strategy based on SICAS model. Southeast communication, (8), 140-142. https://doi.org/10.13556/j.cnki.dncb.cn35-1274/j.2012.08.028

Wang, J. W., \& Chen, H. (2013). The opportunity and Countermeasure of brand communication under SoLoMo Trend. Contemporary communication, (2), 95-96-103.

Wang, Q. (2013). Research on experiential advertising communication strategy based on SICAS model. Mass literature, (10), 99-100.

Yan, X. X., Hu, Z. Q., Xu, X., \& Liu, J. Y. (2017). Research on the Social E-commerce Marketing Model Based on SICAS Model in China. International Journal of Marketing Studies, 9(3), 113-123. 
https://doi.org/10.5539/ijms.v9n3p113

Yang, Y. H. (2011). Exploration of enterprise socialized marketing model based on SICAS model. E-commerce, (12), 26-27. https://doi.org/10.14011/j.cnki.dzsw.2011.12.019

Zhang, B., \& Liu, B. F. (2014). Research on the marketing model of tourism micro-blog based on SICAS model. E-commerce, (11), 31-32.

Zhang, C. X., \& Bi, K. L. (2016). Research on marketing strategy of Yunnan tourism Weibo based on SICAS model. Statistics and Management, (9), 86-88. https://doi.org/10.14011/j.cnki.dzsw.2011.12.019

Zhang, Q. (2014). Research on mobile Internet advertising marketing. Heilongjiang University,

Zhang, Y. Y. (2013). Analysis of Weibo book marketing from SICAS model. Publishing Research, (4), 36-39.

\section{Copyrights}

Copyright for this article is retained by the author(s), with first publication rights granted to the journal.

This is an open-access article distributed under the terms and conditions of the Creative Commons Attribution license (http://creativecommons.org/licenses/by/4.0/). 